\title{
Profissionalização política: social background, carreiras e trajetórias ${ }^{1}$
}

\section{Political professionalization: social background, careers and pathways}

\author{
Alison Ribeiro Centeno ${ }^{2}$
}

Resumo

\begin{abstract}
Debatendo as definições utilizadas em estudos de casos focados no Congresso Nacional, objetiva-se lapidar e propor definições precisas aos conceitos de social background e carreira e trajetória políticas, para levantamentos vindouros nesse frutífero segmento de estudos da Ciência Política. As análises do recrutamento de elites políticas sofrem pela imprecisão desses conceitos-chave, tratados como sinônimos, por vezes utilizados e classificados de acordo com cada autoria, dados seus critérios abertos. O presente artigo apresenta uma demarcação para estudos de carreiras, trajetórias e posição socio-ocupacional, com enfoque no caso brasileiro, revisando parte significativa e importante da literatura nacional e internacional do tema, delineando o social background como titulação escolar, origem regional e profissão prévia à carreira política; elencando a trajetória política como passagem por postos e cargos em associações e entidades não público-burocráticas; e, por fim, a carreira política como os mandatos eletivos e nomeativos ocupados até a eleição para outra posição política.
\end{abstract}

Palavras-chave: Profissionalização política; Carreiras políticas; Trajetórias políticas; Social background; Sociologia política.

\begin{abstract}
Debating definitions used in case studies focused on the National Congress the objective here is to refine and propose precise definitions to the concepts of social background, political career and political pathway for future studies in this fruitful segment of Political Science studies. The analyzes of political elites recruitment suffer from the imprecision of these key concepts, treated as synonyms, sometimes used and classified according to each authorship, given their open criteria. This article presents a demarcation for political careers studies, pathways and socio-occupational position, focusing on the Brazilian case, reviewing a significant and important part of the national and international literature on the subject. Defining the social background as educational degrees, region of origin and profession prior to a political career; listing the political pathway as passage through posts and positions in associations and non-publicbureaucratic entities; and finally the political career as the elective and nominative offices occupied until the election to another political position.
\end{abstract}

Keywords: Political professionalization; Political careers; Political pathways; Social background; Political sociology.

\footnotetext{
${ }^{1}$ Este trabalho deriva da dissertação "Os maestros da elite: carreiras e trajetórias dos líderes no Senado Federal entre 1999 e 2006 ”, sendo o capítulo de revisão bibliográfica que fundamentou a análise empreendida sobre as bancadas das $51^{\mathrm{a}}$ e $52^{\mathrm{a}}$ legislaturas na Casa da Federação.

${ }^{2}$ Doutorando em Ciências Sociais na Pontifícia Universidade Católica do Rio Grande do Sul (PUCRS), Porto Alegre, Rio Grande do Sul, Brasil.E-mail: alison.centeno@edu.pucrs.br
} 


\section{Introdução}

Os estudos sobre elites políticas no Brasil avançam pelas mais diversas frentes: profissionalização política (COSTA; CODATO, 2012; MIGUEL, 2003; PERISSINOTO; VEIGA, 2014), social background (RODRIGUES, 2002, 2009; NEIVA; IZUMI, 2014; CORADINI, 2012), capital familiar (MIGUEL; MARQUES; MACHADO, 2015) e trajetórias políticas (CORADINI, 2007) formam os principais mecanismos para entender a formação da elite parlamentar brasileira. Porém, nem sempre essas 'variáveis' assumem o mesmo sentido na diversidade de estudos que buscam entender o processo de recrutamento político e o que explica a capacidade do sucesso de parte da elite política que ascende, e, sobretudo, permanece nos mais importantes postos de poder.

Desta feita, objetiva-se estabelecer critérios únicos a esses fatores que por vezes adotam maneiras distintas de explicitar as fontes de capitais que se convertem em poder político. Retomam-se estudos de casos focados no Congresso Nacional, sintetizados em dados e afirmações que corroboraram para a compreensão da política institucional brasileira como dominada por uma elite coesa, de baixa circularidade e de recursos socioeconômicos elevados que os projetam para os cargos mais elevados do Legislativo.

Apresenta-se assim um quadro instigante: quanto maior o posto, maior a incidência de períodos longevos de carreira política, diplomação universitária e outras experiências sociais que façam jus ao protagonismo do cargo executado. O presente ensaio estimula lidar separadamente com os dados de carreira política (postos eletivos e nomeativos em instituições públicas), trajetória política (histórico de postos e de cargos em associações e entidades não público-burocráticas) e posição socio-ocupacional ou social background (titulação escolar, profissão e origem regional). Após essa introdução, traz-se o debate sobre a validade de estudar o fenômeno da profissionalização política, considerando a formação de carreiras longevas, assim como o quadro de social background destacado, principais características que os estudos de casos vêm apontando sobre os que chegam ao Congresso Nacional. Encerra-se com as considerações finais - onde é proposto um molde para a pesquisa de antecedentes de mandatos políticos.

\section{Profissionalização e hierarquização: por que estudar elites politicas?}

Inicialmente correlato aos oriundos do meio jurídico, o fenômeno da profissionalização política teve sua abordagem reformulada para se adequar à realidade de onde a própria política passou a ser uma profissão ligada ao histórico social, educacional e profissional anterior à investidura do mandato. Sobretudo como tratado por Michels (1970) e Manin (1995), com contribuições também de Schumpeter (1961) e Dahl (1997), a remuneração parlamentar e os partidos de origem proletária transformaram a política e o perfil dos que são investidos no exercício de mandatos institucionais. Esses adventos permitiram a ascensão de camadas anteriormente fora do meio representativo (CORADINI, 2012), dedicando-se exclusivamente e tendo seus proventos oriundos da atividade política (PERISSINOTTO; VEIGA, 2014).

A elite política pode ser vista como a minoria de pessoas que compartilham o poder (HERRERA, 2004), de prestígio social, vinculada a interesses, e com altas posições institucionais, consequência do status socioeconômico (MILLS, 1965; 1981) - devido aos níveis acadêmicos, a origem territorial, questões profissionais e de gênero (predominantemente masculino). Segundo Herrera (2004), as desigualdades socioeconômicas se traduzem em uma distribuição consequentemente desigual do poder político, sendo a elite política composta por aqueles que formam as instituições representativas e o governo, com componentes de perfil símile, pertencentes às classes abastadas e consideravelmente diferentes das massas da sociedade.

Para Freire (2002, p. 27) a "diferenciação do sistema político" e a profissionalização política entram em contradição evidente com o ideário democrático baseado na plena inclusão. Imputa 
como características explicativas e condicionantes da profissionalização, cargos eletivos, atuação na direção de partidos e em órgãos vinculados a essas agremiações políticas - rememorando Michels (1970), e experiência em cargos estatais, que são a parcela da "modernização do sistema político" (FREIRE, 2002, p. 28). No seio do partido político se forma a contradição que a profissionalização entra em choque com a democratização; em sintonia com Bourdieu (2002), Freire (2002, p. 28) aponta um "certo fechamento da arena política $[\ldots]$ perante as outras esferas da vida social", dado que o capital político se torna um diferencial inigualável para as empreitadas políticas.

A base social dos partidos e o eleitorado cativo das legendas influenciam no tipo de candidatos que são recrutados; ao mesmo tempo, esses "laços que cada organização mantém com a estrutura social" (GAXIE, 2012, p. 190) é o conflito entre as faces da elite, como a intelectual frente à econômica ou dos burocratas contra os profissionais liberais: "dominantes [...] do capital cultural; dominados, do ponto de vista da posse do capital econômico" (GAXIE, 2012, p. 197). Há o antagonismo de membros da elite, controladores de distintos capitais que os projetam no campo político. Influenciado por Bourdieu (2002), Gaxie (2012) descreve um "mercado social" onde as posições dos indivíduos são exercidas de acordo com a origem de cada e as titulações recebidas pelo ensino. Complementa sua lógica com a correlação da "posição social de origem [...] dos políticos [com] as posições ocupadas na hierarquia política" (GAXIE, 2012, p. 165).

Logo, há uma diferenciação antes mesmo da posse do parlamentar; ao analisar as variáveis determinantes para o êxito eleitoral, consideradas como diferenciais entre candidatos derrotados e eleitos, além do peso do financiamento eleitoral (CARLOMAGNO; CODATO, 2018), a posição socio-ocupacional e a experiência política são dois fatores determinantes nas urnas. Analisando os 'caminhos' para o Parlamento - Perissinotto e Miríade (2009) consideram o entendimento das características das elites políticas algo fundamental para compreender o modus operandi do sistema político nacional. Ao analisar o social background dos atores políticos, compreendendo o recrutamento das elites, melhor é o entendimento acerca do que os mesmos descrevem embasados em Dahl (1997) como a poliarquia brasileira.

De fato, um verdadeiro estudo quanto ao "recrutamento político" deve considerar outras etapas além do sufrágio eleitoral, e, mais precisamente, o êxito nas urnas (PERISSINOTTO; COSTA; TRIBESS, 2009). É preciso considerar o perfil socioeconômico dos eleitos, bem como dos membros dos partidos políticos, para então fazer a comparação, seja com os de outros partidos ou até mesmo da população como um todo. Aqui se demonstra um grande empecilho desta área da Ciência Política, devido à dificuldade para obtenção de dados socioeconômicos dos membros dos partidos que não têm seus nomes nas urnas.

Neiva (2011, p. 290) marca como características relevantes do Legislativo brasileiro a centralização na figura do indivíduo, decorrente do sistema de voto em lista aberta, tornando os legisladores "individualistas e autônomos", o que contribui para a formação de carreiras longevas, tornando de extrema relevância o estudo das carreiras políticoinstitucionais, e a passagem por postos eletivos e burocráticos nas esferas do poder público.

Deveras, estudar carreiras políticas envolve propriamente debater o que seria um político de carreira: Allen et al. (2020) propõem uma definição concisa e precisa do conceito, propondo pensar esses atores como desprovidos de outras experiências significantes senão no meio político, oriundos de campos de confluência da atividade política, "ocupando-se e preocupando-se" constantemente com suas ocupações institucionais. Esse é um norte que se soma à teoria da ambição (BLACK, 1979); um político profissional vê, analisa e projeta seu posicionamento no campo político com base nos projetos vindouros ligados à sua cobiça, seja para permanecer no mesmo posto ou se lançar a cargos de maior projeção.

Como mostra Vercesi (2018), as múltiplas formas de estudar carreiras políticas por vezes 
fazem as teorias se sobreporem, mesmo que de fato se complementem. O grande problema é a dissimilaridade do caso brasileiro em relação aos países centrais, especialmente pela alta fragmentação partidária (diferentemente do bipartidarismo dos Estados Unidos, com seu sistema de prévias para cargos legislativos), que levam à necessidade de estabelecer critérios de estudos embasados no modelo de presidencialismo de coalizão, sem fidelidade partidária para cargos majoritários e de um Legislativo que ascende e perde força a depender de quem chefia o Executivo.

Escolhe-se desse modo os estudos sobre a Câmara dos Deputados e o Senado Federal como vias para tecer a construção de critérios específicos para delimitar o social background (posição socio-ocupacional), a trajetória política e a carreira política, podendo tais conceitos serem transladados aos levantamentos de políticos do Executivo, apresentando um mosaico de elites. Quando não o capital econômico eleva indivíduos ao Parlamento, os capitais - social, educacional, religioso e midiático compensam o desprovimento de riquezas, também promovendo a ascensão ao cenário político institucional. Chegados às Casas do Legislativo Federal, como será apresentado no transcorrer do presente ensaio, o capital político se torna o principal mecanismo de manutenção da elite política em seus respectivos postos. $\mathrm{O}$ fenômeno da profissionalização política e o domínio de meios sociais mostram que os partidos no Brasil primeiramente se assemelham optando pelos profissionais do campo político, ainda que mantenham suas claras diferenças quanto ao recrutamento de quadros na sociedade.

Se por um lado os estudos sobre parlamentares eleitos pecam por estudar somente os bemsucedidos no pleito, deixando de fora parte da elite sem êxito (ocasional ou recorrente) ou que sequer entra nas disputas eleitorais, tais levantamentos são a melhor forma de criar um mosaico da elite política. Cervi et al. (2015) propõem pensar a democracia brasileira contemporânea através de três processos: primeiramente, a institucionalização (onde há um movimento de continuidade de políticos e partidos, "engessando" o Parlamento e dificultando a entrada de novas figuras); segundo: a autonomização do meio político (embasado na teoria do autofuncionamento e autorregulação do campo político); por fim, a profissionalização da política, mais especificamente, uma maior taxa de sucesso eleitoral dos 'políticos por profissão', em relação àqueles sem carreira eleitoral, principalmente no Legislativo.

Mesmo entre os profissionais da política, vereadores e deputados estaduais têm desvantagem ao concorrerem com candidatos à reeleição à Câmara dos Deputados ou ao Senado. Mas esta preeminência vai além: estes políticos têm preferência nos grandes partidos, por serem importantes para o crescimento das bancadas, e os mesmos priorizam as grandes legendas, que aumentam suas chances eleitorais, num claro benefício mútuo.

A capacidade dos outsiders está vinculada a questões profissionais e de status econômico (CORADINI, 2012). A influência da posição social é um fator determinante para o triunfo eleitoral, desde a inserção na política, pois a posição social dita as disponibilidades de tempo, recurso e manutenção econômica. Os títulos educacionais e as profissões exercidas, além de outras características sociais, explicam "as formas e os graus de socialização no mundo político [no que] [...] atributos de posição social [...] podem impulsionar ou brecar carreiras políticas" (CODATO; COSTA; MASSIMO, 2014 , p. 347) havendo uma correlação com o cargo pretendido e o quanto a profissão alça esse candidato ao posto almejado.

Não apenas a atividade empresarial é um diferencial para a carreira prévia à entrada na política eleitoral; como demonstra Coradini (2007), parlamentares com títulos universitários valorizados socioeconomicamente, ligados à posição de status social, como profissionais da advocacia e da medicina, também predominam no âmbito do Congresso Nacional. O autor identificou um crescimento do número de parlamentares com histórico de atuação em associações e sindicatos; seu estudo, que abrange a década que vai de 1994 a 2003, apresentou dados importantes no que se refere ao número de ex-representantes de sindicatos de 
funcionários públicos, trabalhadores rurais e urbanos, e, principalmente, de figuras ligadas ao sindicalismo empresarial, eleitos ao longo do período para cadeiras no Congresso Nacional.

É nesse contexto que Codato, Costa e Massimo (2014) também associam a "ocupação" com a carreira política. Os autores inferem que a profissão prévia à entrada no mundo político é correlacionada ao exercício de cargos eletivos e burocráticos, qualificando-os para o desempenho nas instituições, dadas as "habilidades adquiridas" (CODATO; COSTA; MASSIMO, 2014 p. 349). Em uníssono com Weber (2015) e Bourdieu (2002), os autores também apontam para o papel dos advogados, que se destacam nos "parlamentos ocidentais" (CODATO; COSTA; MASSIMO, 2014, p. 349) por sua capacidade de oratória e seu preparo com a elaboração de peças que envolvem questões legislativas.

Miguel (2003) aprofunda esse entendimento abordando as concepções de Bourdieu (2002) de capital político e capital social, em especial como os meios de comunicação (na forma de capital social) servem como trampolim para os outsiders que 'pulam' etapas naturais do processo de formação da carreira política. Os próprios avanços não progressivos na pirâmide dos cargos institucionais políticos, para o autor, devem-se tanto à projeção que certos cargos trazem, quanto à singularidade do momento (exemplo: a alta rejeição de um político incumbido no mandato que tenta reeleição, bem como a projeção que o campo midiático dá ao outsider). Semelhantemente aos exemplos do campo econômico e do campo cultural em Bourdieu (2002), Miguel (2003) mostra as configurações que outras formas de capital se convertem em capital político, fatores que serão rememorados posteriormente ao tratar do capital religioso e do capital midiático nos estudos de Rodrigues (2002, 2009).

Focado na Câmara dos Deputados, este último analisou a composição social dos partidos, apurando as origens socioeconômicas dos deputados na expectativa que essas fossem condizentes com o posicionamento do partido no espectro ideológico esquerda-direita. Rodrigues (2002) encontrou entre os deputados que tomaram posse em fevereiro de 1999 um grande número de professores (indistintamente ao gênero) nos partidos de esquerda, junto a trabalhadores rurais e industriais (principalmente no Partido dos Trabalhadores - PT).

Os profissionais liberais formaram de um quinto à metade da composição social das bancadas estudadas pelo autor, indiferente do posicionamento ideológico dos partidos, muito devido ao grande número de advogados na Casa. Se os profissionais intelectuais se fizeram cada vez mais presentes nos partidos de acordo com o avanço para a esquerda, contrariamente, quanto mais em direção à direita, maior o número de empresários que compunham o background social dos parlamentares.

Rodrigues (2009) voltou a analisar a composição da Câmara dos Deputados através dos resultados das eleições de 1998 e 2002, defendendo haver um paulatino processo de transformação da composição da classe política nacional, decorrente principalmente da incorporação de estratos da classe média e dos setores de baixa renda. Ainda que o movimento (descrito pelo autor como popularização da política no Brasil) tenha levado setores antes estranhos à Câmara Baixa, o próprio não deixa de apresentar constatações muito próximas às de Michels (1970), onde mesmo os representantes das camadas menos abastadas passaram pela socialização entre a elite de suas esferas, distanciando-se gradativamente do trabalho efetivo da divisão que representam.

Desta feita, sua constatação é que não houve uma transformação no recrutamento das legendas partidárias, mas sim uma alteração na composição da Câmara como um todo pelo avanço dos partidos de esquerda e a perda de terreno dos partidos de direita entre o final da década de 1990 e o início dos anos 2000. Trocando em miúdos, a morfologia do Legislativo Federal decorre muito mais do resultado eleitoral do que quaisquer mudanças significativas na sociedade, mostrando que o avanço da classe média e das camadas populares decorreu do movimento de esgotamento da aliança de centro-direita que compôs a gestão de Fernando Henrique Cardoso e a ascensão que ocorria na 
primeira metade da década de 2000 da aliança de centro-esquerda que protagonizou os mandatos de Lula na Presidência da República.

Nada disso retirou o protagonismo dos "quatro grandes grupos profissionais e ocupacionais empresários, profissionais liberais, funcionários do setor público e professores [...] os principais celeiros de abastecimento da classe política brasileira" (RODRIGUES, 2009, p. 49). Profissionais da saúde, membros da classe jurídica, engenheiros, profissionais da educação e os empresários (indistintamente, de pequeno, médio e grande porte), estão em constante contato com a população e/ou dispõem de tempo e flexibilidade em suas profissões para participarem da atividade política (viverem para a política antes de viverem da política).

Avigorando os levantamentos de Bohn (2008) e de Lemos e Ranincheski (2008), Araújo (2011) sinalizou um grande volume de bacharéis em Direito entre os senadores da Nova República, assim como médicos, economistas, engenheiros e administradores. Em sintonia com as afirmações de Rodrigues (2002, 2009) sobre a Câmara dos Deputados, Araújo (2011) identificou no Senado um maior destaque "nas ciências naturais e no magistério" entre os parlamentares de esquerda, havendo paridade entre os senadores formados em "economia, engenharia, medicina e humanidades" (idem, p. 564) nos mais diversos partidos. Também em uníssono com Rodrigues (2002, 2009), confirma o grande número de empresários entre os parlamentares de direita (diferentemente da Câmara, com também elevado grau desses em partidos de centro), enquanto os "advindos da chamada classe trabalhadora - metalúrgicos, comerciários e afins" (ARAÚJO, 2011, p. 565) dominaram os partidos de esquerda.

Desta feita, percebe-se que o social background (posição socio-ocupacional), nas formas de titulação escolar e profissão prévia à carreira institucional, somada a origem regional, não somente distinguem outsiders de políticos profissionais, mas também os partidos no Parlamento. Essa via mostra parte da representação social dos partidos e de suas identidades e, sobretudo, apresenta uma elite parlamentar com capital cultural consideravelmente maior que o eleitorado brasileiro.

Os dados mostrados por Rodrigues (2002, 2009) foram posteriormente corroborados pelo levantamento de Perissinoto e Miríade (2009, p. 312). Avaliando os deputados eleitos em 2006, concluem que em partidos de direita e de centro há "uma posição social mais elevada", enquanto existe "uma tendência a posições sociais médias e baixas nos partidos de esquerda". Universal em todas as linhas ideológicas, está a presença de políticos profissionais: em quase todos os casos foram cerca de metade dos políticos eleitos. Como mostram Allen et al. (2020), um político profissional pode não ser um político de carreira, pois políticos de mandatos ininterruptos podem exercer atividades distintas, especialmente no ramo empresarial e na docência. Isso não retira o protagonismo das longevas carreiras como característica do Congresso brasileiro. Antes de adentrar às carreiras políticas, fala-se de outras vertentes de capitais conversíveis em capital político, mas distintas do social background.

Um ponto importante exposto por Rodrigues (2009) é como o capital religioso se mostrou uma plataforma para ascensão de parlamentares nos partidos de centro e direita, tão importante quanto o sindicalismo para os que obtiveram mandatos pelos partidos de esquerda. Outro capital amplamente conversível em capital político é o capital midiático, ainda que o autor aponte seu pequeno número na composição da Câmara. É importante retratar como os que o possuem dominam princípios basilares do tipo ideal do político profissional, como oratória e persuasão, perpetuados pela literatura weberiana, permitindo a elevação ao Congresso Nacional dessas figuras que mantêm contato indireto (porém constante) com a população.

A "mídia interfere na estrutura da carreira política" (MIGUEL, 2003, p. 116), pois o político com mandato tanto usa os meios midiáticos para se promover e manter seu capital político - sustentando o destaque que busca ter junto ao seu eleitorado cativo (pensando no próximo pleito eleitoral), como por vezes enfrenta em sua tentativa de reeleição aqueles que formaram nela seu capital 
social com a "alta visibilidade midiática". No que a mídia forma potenciais candidatos, ao retroalimentar o capital político daqueles investidos em mandatos, os oriundos do campo midiático enfrentam figuras que passaram pelo "treinamento ou socialização em funções inferiores” (MIGUEL, 2003, p. 128) que apenas a carreira política pode trazer.

Ocorre que praticamente inexistem estudos que vão a fundo nas atividades políticas não institucionais cruciais para empreitadas no campo político, havendo amplo estudo de Coradini (2007), com enfoque em cargos variados (deputado federal, senador e ministros de Estado) e Centeno (2018) voltado para o Senado Federal. As trajetórias políticas, passagens por postos sindicais trabalhistas, diretorias e comandos de entidades empresariais, assessorias políticas etc., são viveiros das carreiras políticas, pontapé inicial em carreiras eletivas e nomeativas no meio burocrático e institucional. Mesmo seu maior empecilho - a dificuldade de obtenção de informações sobre atividades pregressas à carreira política, justifica a necessidade de 'garimpar' tais informações que apresentam as gêneses das carreiras políticas, a socialização que encaminha e serve como catapulta para as disputas institucionais.

Na Câmara dos Deputados, a profissionalização nos moldes de Weber (2015) se estendeu até ao PT (MIGUEL, 2003), que no pós-ditadura tinha quase em plenitude estreantes nas urnas entre os eleitos - trazendo à tona como fato histórico a "estrutura em movimento" apontada por Panebianco (2005), "gênese" 'versus' "institucionalização" (idem, p. 92), onde o partido, como bem descrito por Michels (1970), intenciona o crescimento e se burocratiza para ser mais competitivo.

Lemos e Ranincheski (2008) analisaram as carreiras políticas dos senadores eleitos ao longo da década de 1990 para constatar que os senadores, além de mais experientes que os deputados, quando analisado o seleto número de indicados para a Comissão de Constituição e Justiça (CCJ) durante o período em estudo, dispunham carreiras ainda mais longevas no meio político. Tal constatação é um indício de quanto mais importante o papel desempenhado pelo senador dentro da Casa, maior a profissionalização política e o que as autoras intitulam como socialização política - os cargos obtidos nas urnas ou por nomeação dessas figuras em estudo.

A metodologia adotada pelas autoras conflita com a compreensão aqui sendo utilizada, já que o social background descrito pelas mesmas está focado na carreira institucional do político e não nos perfis sociodemográficos que promoveram esses indivíduos do campo social ao campo político. Esse empecilho não impede de utilizar algumas das verificações por elas levantadas, que detectaram na "expertise política de que são portadores" os senadores em estudo, um "intercruzamento entre os poderes Legislativo e Executivo" (LEMOS; RANINCHESKI, 2008, p. 88) na formação de suas carreiras. A expertise legislativa e a formação de carreiras duradouras advêm também do maior tempo de mandato dos senadores em relação aos deputados (LLANOS; SÁNCHEZ, 2008); os primeiros não precisam pensar imediatamente na próxima eleição, tendo tempo mais flexível para driblarem crises envoltas em suas figuras ou em seus partidos.

De tal forma, Lemos e Ranincheski (2008, p. 97) apuraram o já esperado perfil destoante dos senadores com a "morfologia social brasileira, com parlamentares majoritariamente homens, com média de idade acima dos cinquenta anos, quase em sua totalidade com formação até o ensino superior”. Quando voltadas para a carreira institucional desses políticos, as autoras optaram por resumir o curriculum dos parlamentares, agrupando os dados por esfera (valendo assim o mais alto cargo ocupado por cada político no Executivo e no Legislativo); tal simplificação pode distorcer o estudo, pois encobre pontos importantes das carreiras.

Um senador que passou por toda linha legislativa não pode ser igualado a um que começou de imediato como deputado federal. O primeiro, muito provavelmente teve como grande benefício para obtenção de seu mandato a construção de uma carreira política, galgando posições ao longo dos anos através de disputas eleitorais; no segundo exemplo, há o possível benefício da trajetória política que 
serve como vitrine para chegar imediatamente no cargo com votação proporcional de maior prestígio na República, antes de ascender ao único posto majoritário do Legislativo.

A escolha para estudar as carreiras dos senadores por Llanos e Sánchez (2008) incorre no mesmo método abreviativo de Lemos e Ranincheski (2008); os primeiros definiram como experiência o quão elevado foi o último cargo político, preferencialmente se o parlamentar foi reeleito para o cargo de senador. A quadra de autores trabalhou como experiência a importância do membro na passagem pela hierarquia dos cargos públicos, todavia, há figuras que construíram suas carreiras nas urnas, outras em cargos importantes junto às esferas estadual e federal, o que faz com que essa sintetização deixe de captar a trilha que formou determinado protagonismo político.

A condensação dos dados das carreiras pode ser algo perigoso, pois no que os autores dividiram os "Senadores vindos, [...] de um cargo de menos experiência, como a Câmara dos Deputados [em] [...] classificados somente como tendo mais experiência se eles tiveram a oportunidade de ocupar os cargos de Ministros" (LLANOS; SÁNCHEZ, 2008, p. 141), permite que um outsider que ascende a um Ministério e posteriormente seja eleito senador, tenha maior relevância na análise do que um deputado várias vezes reeleito. Mesmo que valorizando status do posto ao invés da longevidade na política, Lemos e Ranincheski (2008) descreveram o Senado brasileiro como "uma casa muito elitista" (idem, p. 144) tanto pela experiência política quanto pelo grande número de bacharéis em Direito, economistas, engenheiros e médicos.

Araújo (2011) também incide nesse mesmo vício reducionista, valendo-se do posto mais alto ocupado por um senador na hierarquia dos cargos, abstraindo assim dados de construção de carreiras, valorizando o status que o mais elevado posto traz à biografia do parlamentar imediatamente antes de seu mandato no Senado. Quase dois terços dos senadores estudados tiveram experiência em "cargos legislativos antes de atuarem no Senado" (ARAÚJO, 2011, p. 571), com menor experiência entre os senadores dos partidos de esquerda, em parte justificável pelo período analisado pelo autor abarcar o pós-ditadura, onde muitos políticos da esquerda estavam reassumindo seus direitos de concorrer a mandatos eletivos.

Segundo Costa e Codato (2012), o Senado se diversifica mais quando há duas cadeiras em disputa na eleição, diminuindo assim o número de empresários na proporção da composição da Casa - e de acordo com Llanos e Sánchez (2008, p. 17), também o número de homens; quando na eleição há apenas uma cadeira sendo concorrida, sobrepõem-se os quadros mais tradicionais. Consequentemente, com o aumento do número de políticos com carreiras mais extensas, os autores afirmam que o Senado vem se fechando para os "políticos ocasionais (outsiders, franco atiradores, etc.)", reforçando as constatações de Rodrigues (2002, 2009) e - Perissinoto e Miríade (2009), ao mesmo passo que vai ao encontro do levantamento de Cervi et al. (2015), mostrando a dominação dos políticos profissionais - semelhantemente ao levantamento de Araújo (2011), quanto mais à direita do espectro ideológico, maior o índice de carreiras mais longas na política.

Logo, o estudo das carreiras políticas fornece uma informação precisa para além das raízes sociais que embasam o lançamento na vida políticoinstitucional, põe em evidência através dos cargos eletivos e nomeativos o caminho traçado, a ascensão ou o declínio de políticos que por priorizarem estritamente o meio político como âmbito de atuação, tomam esse exercício como profissão e buscam sequencialmente cargos que os mantenham relevantes no campo político. As carreiras políticas são o recurso indelével do capital político, estritamente delimitadas nos cargos institucionais, fornecem a melhor maneira de mensurar expertise política e distinguir políticos profissionais e outsiders.

Certamente um dos pontos mais importantes e que reforça a relevância da experiência política é a detecção de Costa, Costa e Nunes (2014), onde indiferente da profissão prévia ou titulação escolar, a experiência política dos senadores é análoga. Isso recai nas literaturas de Panebianco (2005) e 
Schumpeter (1961), em especial o primeiro que explanou a elitização política como regularidade, prognose da estratégia e da disputa política para formação e manutenção de lideranças.

Compreende-se, assim, que na hierarquia dos cargos a experiência política é primordial. A disputa ao Senado Federal privilegia os políticos profissionais, inclusive sendo o capital político o fator que contrabalança o privilégio dos recursos socioeconômicos, para além de permitir maior diversidade de gênero na Casa da Federação. Contudo, como evidenciado segundo os levantamentos aqui apresentados, quanto mais restrita a eleição, maior a incidência dos quadros tradicionais, pois se o Senado se mostra mais restrito que a Câmara às diversidades sociais, por serem 81 membros (três por cada Unidade da Federação), se a disputa se fecha a apenas uma cadeira por eleição, ainda maiores são as chances de repetição da vitória daqueles de perfis habituais.

Logo em seguida, os diplomas universitários serviram como maior utensílio dentre o capital social para projeção no campo político, em especial entre os parlamentares de esquerda, outrora excluídos do processo político. Porém, novamente incorrendo na estratégia relatada por Panebiano (2005) e em sintonia com o estudo de caso de Lemos e Ranincheski (2008) sobre a CCJ do Senado, aos partidos (principalmente aqueles com chances de chegada ao Palácio do Planalto) é pertinente recrutar quadros bem formados. Nas comissões permanentes, a agenda de votação requer um mínimo de conhecimento técnico e familiaridade com questões burocráticas para o bom trâmite das matérias de interesse do Executivo. Tudo isso reforça o Senado como uma casa de elite, se não da elite política formada pelos de longa carreira, da elite social.

De fato, é possível observar traços das teorias de Schumpeter (1961) e Sartori (1994) quando se analisam os levantamentos da composição do Parlamento brasileiro pós-ditadura (1964-1985/1989) até a primeira década do século XXI, já que o meio político esteve alcançável não apenas aos mais abastados, mas aos que tiveram a "vontade eficaz" (SCHUMPETER, 1961, p. 318) que o economista austríaco colocou como pressuposto para o bom andamento do regime democrático, considerando a presença de professores e sindicalistas operários no Congresso Nacional.

Todavia, valendo-se da "dimensão vertical da política” (SARTORI, 1994, p. 181), não apenas uma minoria regeu uma maioria social, mas a hierarquização social prevaleceu como via para chegada ao Parlamento. Mesmo entre os partidos de esquerda que recrutaram maior número de indivíduos que não compunham o rol de profissões ligadas a altos recursos econômicos, como mostrado por Rodrigues $(2002,2009)$ e embasado em Gaxie (2012), quando esses não se encontravam no topo da pirâmide do poderio econômico, distinguiramse pelos recursos educacionais.

Aqui não cabe juízo de valor sobre o que melhor seria para a representação política, mas sim atestar que na hierarquia da política institucional, a fim de chegar aos mais altos cargos eletivos, há caminhos a serem trilhados no intuito de construir recursos e 'capitais' que estruturem essa chegada. Seja o capital político (carreira política - construída nas urnas e nos postos da burocracia institucional), o capital social - que se desdobra na trajetória política (redes as quais o indivíduo pertence e que lhe projetam para o pleito eleitoral) ou o social background (titulações educacionais e histórico profissional que assentam o caminho a ser percorrido pelo futuro político profissional).

\section{Considerações finais}

Vários autores, produtores de diversos estudos quanto ao social background dos políticos eleitos, foram utilizados para reforçar a necessidade de compreender os antecedentes desses que eventualmente assumiram a política como profissão. Apresentou-se o Congresso Nacional composto por aqueles que, quando não ligados ao domínio econômico, eram providos pela instrução educacional.

O social background pode inicialmente explicar a maior disposição de recursos para o indivíduo passar a se dedicar à política, porém, 
deve também ser considerado como diferencial para a disputa interna dos assentos que os partidos dispõem nas instituições, principalmente para as indicações às comissões temáticas. Seu estudo concomitante às trajetórias políticas, aspectos que juntos moldam o capital social, combinado com os levantamentos das carreiras político-institucionais, são basilares para o entendimento do que diferencia eleitos e não eleitos, e dentre os que obtêm êxito nas urnas, como esses se distribuem nos postos das instituições as quais pertencem.

Conforme sintetizado na revisão bibliográfica apresentada na seção anterior, em termos de formação e atuação profissional prévia à carreira política, essas atividades produzem know-how de política, não necessariamente na interação políticoeleitor e convívio entre membros do Parlamento, mas de domínio das questões socioeconômicas tratadas - no que lembra Schumpeter (1961) - no cotidiano da política. É frutífero ao partido político ter quadros formados e anteriormente atuantes em áreas específicas. Assim como os advogados na Comissão de Constituição e Justiça (CCJ), os engenheiros podem ser primordiais na Comissão de Serviços de Infraestrutura (CI) e os economistas na Comissão de Assuntos Econômicos (CAE).

As outras formas de capital 'conversíveis' em capital político expõem as características das trajetórias políticas da elite que ascende e faz carreira nos postos institucionais/eletivos. Atuantes em associações e redes que os colocam em contato com seus potenciais eleitores, oriundos de sindicatos, igrejas, dos programas de rádio e televisão etc., até mesmo as assessorias políticas e os postos em gabinetes (CENTENO, 2018) costumam marcar a trajetória daqueles que 'pulam etapas' e alcançam posições políticas de prestígio sem começar pela base da hierarquia dos cargos disputados nas urnas.

Enquanto os levantamentos de carreiras políticas se beneficiam pela facilidade de averiguar, esquematizar e quantificar os postos eletivos e nomeativos, tornando-se a variável mais simples para o entendimento da profissionalização política, a análise das trajetórias é mais eficaz para averiguar os caminhos dos outsiders, considerando sua total inexperiência política, até de cargos de nomeação. Indiferente da profissão ou do título escolar, esses transformam seu capital social em capital político, valendo-se dos benefícios dos contatos pessoais, prática da oratória, flexibilização de suas agendas, popularidade no meio social e das portas que suas trajetórias abrem.

O levantamento aqui apresentado demonstra que os estudos de casos referentes ao Congresso Nacional conversam entre si, tendo como denominador comum os antecedentes aos mandatos, no entanto, adotam perspectivas e nomenclaturas distintas enquanto almejam objetivos semelhantes. Espera-se, findado o presente ensaio, embasado na literatura clássica que é também comum aos estudos expostos, colaborar para um melhor delineamento dessas que são as principais variáveis de avaliação da profissionalização política.

\section{Referências}

ALLEN, N.; MAGNI, G.; SEARING, D.; WARNCKE, P. What is a career politician? Theories, concepts, and measures. European Political Science Review, Cambridge, v. 12, n. 2, p. 199-217, 2020. Doi: https:// doi:10.1017/S1755773920000077. Disponível em: https://bit.ly/3otW5hV. Acesso em: 9 ago. 2021.

ARAÚJO, P. M. Recrutamento parlamentar para o Senado e o perfil dos senadores brasileiros, 19892006. Revista Política Hoje, Recife, v. 20, n. 2, p. 550-580, 2011. Disponível em: https://bit. ly/3a5BKag. Acesso em: 16 set. 2017.

BLACK, G. S. A Theory of political ambition: career choices and the role of structural incentives. The American Political Science Review, New York, v. 66, n. 1, p. 144-159, 1972. Doi: https://doi. org/10.2307/1959283. Disponível em: https://bit. ly/3A9rMiz. Acesso em: 8 ago. 2021.

BOHN, S. Mulheres e qualidade das candidaturas nas eleições para o Senado: Brasil e Estados Unidos em contraste. In: LEMOS, L. B. (org.). O Senado Federal brasileiro no pós-constituinte. Brasília: UniLegis - Senado Federal, 2008. p. 151-202.

BOURDIEU, P. O poder simbólico. Rio de Janeiro: Bertrand Brasil, 2002. 
CARlOMAGNO, M; CODATO, A. Profissão, sexo e dinheiro: mensuração da acumulação de desigualdades na competição eleitoral brasileira. Colombia Internacional, Bogotá, n. 95, p. 79-107, jul. 2018. https://doi.org/10.7440/colombiaint95. 2018.04. Disponível em: https://bit.ly/3mkhIyx. Acesso em: 08 ago. 2021.

CENTENO, A. R. Os maestros da elite: carreiras e trajetórias dos líderes no Senado Federal entre 1999 e 2006. 2018. Dissertação (Mestrado em Ciências Sociais) - Pontifícia Universidade Católica do Rio Grande do Sul, Porto Alegre, 2018.

CERVI, E. U.; COSTA, L. D.; CODATO, A.; PERISSINOTTO, R. Dinheiro, profissão e partido: a vitória na eleição para deputado federal no Brasil em 2010. Sociedade e Estado, Brasília, v. 30, n. 1, p. 189-205, abr. 2015. Doi: http://dx.doi.org/10. 1590/S0102-69922015000100011. Disponível em: https://bit.ly/3owXaW0. Acesso em: 28 mar. 2016.

CODATO, A.; COSTA, L. D.; MASSIMO, L. Classificando ocupações prévias à entrada na política: uma discussão metodológica e um teste empírico. Opinião Pública, Campinas, v. 20, n. 3, p. 346-362, dez. 2014. Doi: https://dx.doi.org/10.1590/180701912014203346

CORADINI, O. L. Categorias sócio-profissionais, titulação escolar e disputas eleitorais. Revista de Sociologia e Política, Curitiba, v. 20, n. 41, p. 109122, fev. 2012. Doi: http://dx.doi.org/10.1590/S0 104-44782012000100008. Disponível em: https:// bit.ly/3DbxHFW. Acesso em: 12 mar. 2016.

CORADINI, O. L. Engajamento associativosindical e recrutamento de elites políticas. Revista de Sociologia e Politica, Curitiba, n. 28, p. 181203, jun. 2007. Doi: https://dx.doi.org/10.1590/ S0104-44782007000100012. Disponível em: https://bit.ly/3D9QjWF. Acesso em: 13 abr. 2016.

COSTA, L. D.; CODATO, A. Profissionalização ou popularização da classe política brasileira? Um perfil dos senadores da República. Textos para Discussão, Curitiba, n. 2, p. 1-28, abr. 2012. Disponível em: https://bit.ly/3B9XMEJ. Acesso em: 18 set. 2017.

COSTA, P. R. N.; COSTA, L. D.; NUNES, W. Os senadores-empresários: recrutamento, carreira e partidos políticos dos empresários no Senado brasileiro (1986-2010). Revista Brasileira de Ciência Política, Brasília, n. 14, p. 227-253, maio/ago. 2014. Disponível em: https://bit.ly/316pFHX. Acesso em: 16 set. 2017.

DAHL, R. Poliarquia: participação e oposição. São Paulo: EdUSP, 1997.

FREIRE, A. A profissionalização política dos deputados portugueses. Sociologia: Revista da Faculdade de Letras da Universidade do Porto, Porto, v. 12, p. 27-56, 2002. Disponível em: https://bit. ly/318ndB2. Acesso em: 8 ago. 2017.

GAXIE, D. As lógicas do recrutamento político. Revista Brasileira de Ciência Política, Brasília, n. 8, p. 165-208, ago. 2012. Doi: http://dx.doi. org/10.1590/S0103-33522012000200007. Disponível em: https://bit.ly/3A8ueGb. Acesso em: 25 ago. 2017.

HERRERA, J. S. La élite parlamentaria de Canarias. Revista de Sociologia e Política, Curitiba, n. 23, p. 141-153, nov. 2004. Doi: http://dx.doi. org/10.1590/S0104-44782004000200013. Disponível em: https://bit.ly/2YijYOt. Acesso em: 28 mar. 2016.

LEMOS, L. B. S; RANINCHESKI, S. Carreiras políticas no Senado brasileiro: um estudo das composições do Plenário e da Comissão de Constituição, Justiça e Cidadania na década de 90. In: LEMOS, L. B (org.). O Senado Federal brasileiro no pós-constituinte. Brasília: UniLegis - Senado Federal, 2008. p. 87-121.

LLANOS, M.; SÁNCHEZ, F. Conselho de anciãos? O Senado e seus parlamentares no Cone Sul. In: LEMOS, L. B (org.). O Senado Federal brasileiro no pós-constituinte. Brasília: UniLegis Senado Federal, 2008. p. 87-121.

MANIN, B. As metamorfoses do governo representativo. Revista Brasileira de Ciências Sociais, São Paulo, v. 10, n. 29, p. 5-34, 1995. Disponível em: https://bit.ly/2YohDSn. Acesso em: 20 out. 2016.

MICHELS, R. Os partidos políticos. São Paulo: Senzala, 1970.

MIGUEL, L. F. Capital político e carreira eleitoral: algumas variáveis na eleição para o Congresso brasileiro. Revista de Sociologia e Política, Curitiba, 
n. 20, p. 115-134, jun. 2003. Doi: http://dx.doi. org/10.1590/S0104-44782003000100010. Disponível em: https://bit.ly/3iv5aDp. Acesso em 26 ago. 2017.

MIGUEL, L. F.; MARQUES, D.; MACHADO, C. Capital familiar e carreira política no Brasil: gênero, partido e região nas trajetórias para a Câmara dos Deputados. Dados, Rio de Janeiro, v. 58, n. 3, jul./set. 2015. Doi: https://doi.org/10. 1590/00115258201557. Disponível em: https://bit. ly/3AdLaej. Acesso em: 15 mar. 2016.

MILLS, C. W. A elite do poder. Rio de Janeiro: Zahar Editores, 1981.

MILLS, C. W. Poder e política. Rio de Janeiro: Zahar Editores, 1965.

NEIVA, P. R. P. Coesão e disciplina partidária no Senado Federal. Dados, Rio de Janeiro, v. 54, n. 1, p. 289-318, 2011. Doi: http://dx.doi.org/10.1590/ S0011-52582011000200003. Disponível em: https://bit.ly/3a5IQeU. Acesso em: 15 mar. 2016.

NEIVA, P.; IZUMI, M. Perfil profissional e distribuição regional dos senadores brasileiros em dois séculos de história. Revista Brasileira de Ciências Sociais, São Paulo, v. 29, n. 84, p. 165188, fev. 2014. Doi: http://dx.doi.org/10.1590/ S0102-69092014000100011. Disponível em: https://bit.ly/3mEDMEj. Acesso em: 16 set. 2017.

PANEBIANCO, A. Modelos de partido: organização e poder nos partidos políticos. São Paulo: Martins Fontes, 2005.

PERISSINOTTO, R. M.; VEIGA, L. F. Profissionalização política, processo seletivo e recursos partidários: uma análise da percepção dos candidatos do PT, PMDB, PSDB e DEM nas eleições para Deputado Federal de 2010. Opinião Pública, Campinas, v. 20, n. 1, p. 49-66, abr. 2014. Doi: http://dx.doi.org/10.1590/S0104-627620140001 00003

PERISSINOTTO, R.; MIRÍADE, A. Caminhos para o parlamento: candidatos e eleitos nas eleições para deputado federal em 2006. Dados, Rio de Janeiro, v. 52, n. 2, p. 301-333, jun. 2009. Doi: http:// dx.doi.org/10.1590/S0011-52582009000200002. Disponível em: https://bit.ly/3FgQukZ. Acesso em: 15 mar. 2016.
PERISSINOTTO, R.; COSTA, L. D.; TRIBESS, C. Origem social dos parlamentares paranaenses (1995-2006): alguns achados e algumas questões de pesquisa. Sociologias, Porto Alegre, v. 11, n. 22, p. 280-313, jul./dez. 2009. Doi: https://dx.doi. org/10.1590/S1517-45222009000200011. Disponível em: https://bit.ly/3DeUDEj. Acesso em: 13 abr. 2016.

RODRIGUES, L. M. Mudanças na classe política brasileira. Rio de Janeiro: Centro Edelstein de Pesquisas Sociais, 2009. Disponível em: https:// bit.ly/3la2OLM. Acesso em: 20 set. 2017.

RODRIGUES, L. M. Partidos, ideologia e composição social. Revista Brasileira de Ciências Sociais, São Paulo, v. 17, n. 48, p. 31-47, fev. 2002. Doi: http://dx.doi.org/10.1590/S0102-690920020001 00004

SARTORI, G. A teoria da democracia revisitada: o debate contemporâneo. São Paulo: Ática, 1994. v.1

SCHUMPETER, J. Capitalismo, socialismo e democracia. Rio de Janeiro: Fundo de Cultura, 1961.

VERCESI, M. Approaches and lessons in political career research: Babel or pieces of a patchwork? Revista Española de Ciencia Política, n. 48, p. 183206, nov. 2018. Doi: https://doi.org/10.21308/ recp.48.07

WEBER, M. A Política como vocação. In: WEBER, M. Ciência e política: duas vocações. São Paulo: Cultrix, 2015.

\section{Agradecimentos}

Profundo agradecimento aos pareceristas anônimos que trouxeram excelentes colocações, enobrecendo o artigo e provocando reflexões que se estenderão a outros trabalhos futuros.

O presente trabalho foi realizado com apoio da Coordenação de Aperfeiçoamento de Pessoal de Nível Superior - Brasil (CAPES) - Código de Financiamento 001.

Recebido em: 18 jan. 2021

Aceito em: 15 set. 2021 